\title{
Human cytomegalovirus: Drug resistance and new treatment options using natural products
}

\author{
SILVIYA STOEVA ${ }^{1}$ and THOMAS EFFERTH ${ }^{2}$ \\ ${ }^{1}$ University of Heidelberg, Institute of Pharmacy and Molecular Biotechnology; \\ ${ }^{2}$ German Cancer Research Center, Pharmaceutical Biology (C015), Heidelberg, Germany
}

Received July 23, 2008; Accepted August 27, 2008

DOI: $10.3892 / \mathrm{mmr} 00000028$

\begin{abstract}
Human cytomegalovirus (HCMV), a member of the ß-herpesvirus family, is a cause of high morbidity and mortality rates among immunosuppressed individuals and patients with acquired immunodeficiency syndrome (AIDS). Despite the availability of approved antiviral drugs, treatment of HCMV infections remains difficult. Antiviral therapies are in part limited by the small number of available drugs showing satisfactory clinical results . Other factors, such as low potency, poor oral bioavailability and the emergence of drug resistance, also contribute significantly to the obstacles confronting current therapies for HCMV infection. In search of new drugs for the treatment of HCMV infection, researchers have turned their attention to natural products. Unfortunately, not many natural compounds have proven to be efficacious against HCMV. Those that have shown good results in vitro are reviewed here, and their molecular targets and mechanisms of action are discussed along with those of established antiviral agents.
\end{abstract}

\section{Contents}

1. Introduction

2. Treatment

3. Resistance mechanisms

4. Natural products

5. Conclusions

\section{Introduction}

Human cytomegalovirus (HCMV) infection is characterized by the depolymerization of actin filaments (1). This results in the disruption of the cytoskeleton of infected cells, causing the

Correspondence to: Dr Thomas Efferth, German Cancer Research Center, Pharmaceutical Biology (C015), Im Neuenheimer Feld 280, 69120 Heidelberg, Germany

E-mail: t.efferth@dkfz.de

Key words: antiviral agents, chemotherapy, drug resistance, human cytomegalovirus, natural products, pharmacognosy cells to appear bigger and giving the virus its name, formed from the Greek words 'cyto', meaning cell, and 'mega', or big (2). Typically, a primary infection with HCMV proceeds asymptomatically. The latent virus can remain in infected cells for years or even a lifetime. However, in the absence of an adequate immune response the virus can be reactivated, leading to hepatitis and liver failure, colitis, pneumonitis in lung transplant patients, retinitis in AIDS patients and, eventually, death $(3,4)$. Infection with HCMV is therefore common among HIVinfected individuals and immunosuppressed patients who have undergone transplantation or chemotherapy (5). Transmission of the infection can occur in many ways: i) via blood during transplants, which may lead to allograft rejection and a predisposition to malignancies $(4,6,7)$, ii) via body fluids such as urine, saliva, semen, vaginal secretions, tears and breast milk, in which the virus is shed after infection, and iii) via the placenta of a mother to her unborn child, which often causes severe congenital defects including blindness, deafness, mental retardation and motor disabilities $(4,5)$.

\section{Treatment}

Antiviral agents. Treatment of cytomegalovirus is complicated by the limited number of treatment options. The antiviral drugs currently in use for HCMV infections are ganciclovir (GCV), cidofovir (CDV) and foscarnet (FOS), whose mechanisms of action are all well understood (Fig. 1). GCV and its valine ester prodrug, valganciclovir, are the antiviral agents most commonly used against CMV infection (8). GCV is a deoxyguanosine analogue phosphorylated upon entry into the infected cell by an HCMV UL97 gene-encoded phosphotransferase. Subsequently, cellular kinases phosphorylate the monophosphate to a final triphosphate. Once phosphorylated, GCV competes with deoxynucleotide triphosphates (dNTPs) for the dNTP binding site of the viral DNA polymerase. The incorporation of GCV into the DNA polymerase inhibits viral DNA replication $(3,9)$.

Unfortunately, not all patients respond well to treatment with GCV. In such cases, CDV is applied (10). CDV is a cytidine analogue and, like GCV, its phosphorylated form is a competitive inhibitor of HCMV DNA polymerase $(4,11)$. However, unlike GCV, CDV is not activated by UL97, and undergoes only two phosphorylation steps by cellular kinases.

Lastly, FOS is a pyrophosphate analogue that does not need to be activated in order to exert its antiviral activity. Its 


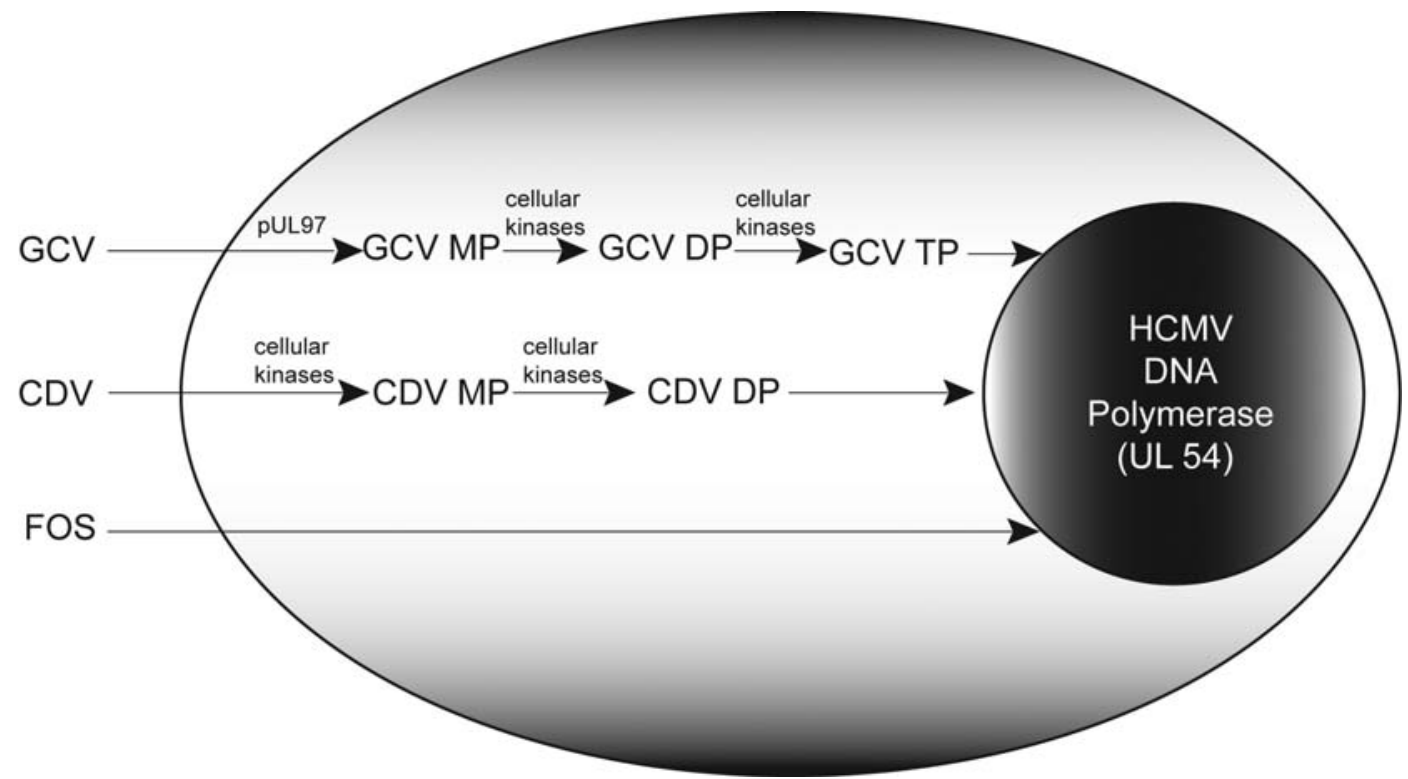

Figure 1. Schematic representation of the mechanisms of action of ganciclovir (GCV), cidofovir (CDV) and foscarnet (FOS). Upon entering an infected cell, GCV is phosphorylated by the UL97 gene product and, consequently, by cellular kinases. CDV needs activation only by cellular kinases. Like GCV, its phosphorylated form can compete with dNTPs for the dNTP binding site of the HCMV DNA polymerase. In contrast, FOS does not need activation to block the HCMV DNA polymerase and inhibit the building of the viral DNA.

mechanism of action also differs from that of GCV or CDV in that it binds and blocks the pyrophosphate binding site at the viral DNA polymerase (Fig. 1), preventing the incorporation of incoming dNTPs into the viral DNA $(3,12)$.

A fourth antiviral drug, formivirsen, has also been developed. However, unlike GCV, CDV and FOS, it is used only in the treatment of retinitis in AIDS patients. Formivirsen is a 21 antisense nucleotide and does not inhibit viral DNA polymerase, but rather complementarily binds the HCMV immediate-early mRNA responsible for the expression of viral proteins, thus interfering with HCMV replication at an early stage $(4,10)$.

Other antiviral drugs, such as naphthalene and benzamidazole derivatives, are currently being developed. Further investigation into the efficacy of these antiviral drug candidates is needed; however, among them maribavir stands out as having better oral bioavailability, lower toxicity and higher potency than the presently approved antiviral drugs (13). Although its mechanism of action is not well understood, experimental results suggest that the efficacy of maribavir against cytomegalovirus infection is probably based on the inhibition of viral DNA synthesis and capsid nuclear exit $(14,15)$.

Therapeutic approaches. As previously mentioned, patients who are immunosuppressed due to a disease such as AIDS or due to post-transplantation therapy are especially endangered by the reactivation of a latent cytomegalovirus. Three main approaches have been adopted for the management of HCMV infection and disease: i) prophylaxis, which is based on the administration of an antiviral drug prior to the detection of HCMV infection to suppress viral replication, ii) preemptive treatment, which is initiated when an asymptomatic cytomegalovirus infection is detected by means of specific laboratory analysis including a viral antigen detection test (16), and iii) 'deferred' treatment, referring to the treatment of an established disease, which is applied after cytomegalovirus disease has become clinically apparent. At present, all three therapies have their supporters. However, it is generally accepted that preemptive treatment has the best results, simply because unnecessary antiviral toxicity and the emergence of drug resistance are avoided $(4,17)$.

\section{Resistance mechanisms}

Drug resistance is in large part the main challenge facing the treatment of HCMV. The susceptibility of cytomegalovirus to the abovementioned antiviral agents depends on mutations in the UL97 and UL54 genes. The proteins encoded by these genes are involved in the replication of viral DNA.

Mutations in the gene encoding the viral kinase UL97 lead to lower levels of GCV phosphorylation, hinder the generation of its triphosphate active form, and eventually prevent the inhibition of viral DNA polymerase. The UL97 gene contains eight highly conserved regions with homology to tyrosine kinases and bacterial phosphotransferases (18). The most common mutations are found in region IX at codons 594 and 595, and in region VIII at codon 520. Frequently, mutations appear at codons 592 and 603 (3). Mutations at codons 490 and 520 are associated with the ability to bind ATP, while those at codons 590 to 607 are responsible for substrate recognition (3).

In comparison to the $U L 97$ gene, mutations in the gene coding the viral DNA polymerase UL54 are much less common (19). Therefore, their influence on the development of drug resistance has yet to be thoroughly studied. It is known that, in combination with $U L 97$ mutations, they cause high levels of antiviral drug resistance. As with UL97, the cytomegalovirus DNA polymerase gene contains eight conserved regions. Mutations in regions IV and $\mathrm{V}$ are thought to be mainly associated with the emergence of GCV and CDV cross resistance, as both drugs compete with dNTPs for their 
<smiles>O=c1c(O)c(-c2ccc(O)cc2)oc2cc(O)cc(O)c12</smiles>

Kaempferol<smiles>[R]Oc1ccc(C2Oc3cc([R20])cc([R])c3C(=O)C2c2c([R])cc(O[R])c3c(=O)cc(-c4ccc([R6])cc4)oc23)cc1</smiles>

Volkensiflavone<smiles>[R]c1ccc2c(c1O)C(=O)c1cc3c(O)cc(C)cc3c(O)c1C2=O</smiles>

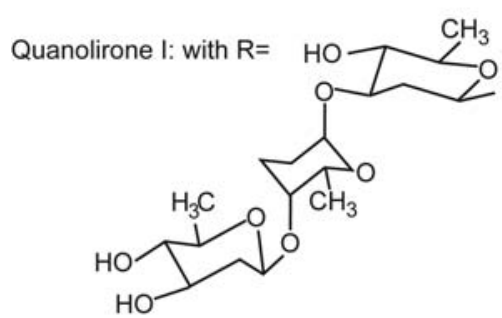

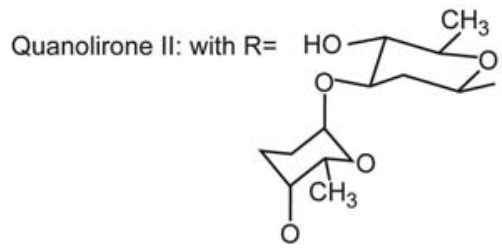<smiles>CNC(=O)CC1NC(=O)C(=C2C=CC(C)C(C(C)C)O2)C1=O</smiles>

E-form

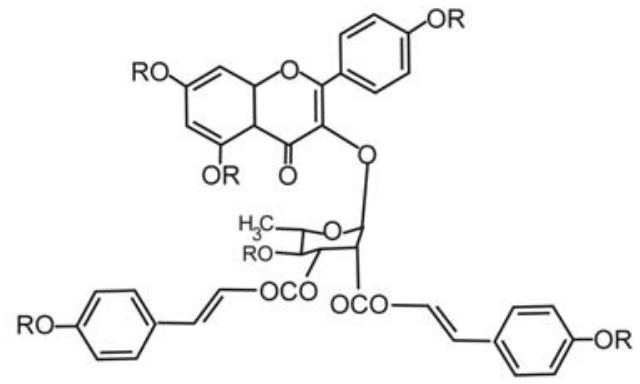

Flavonoid from the Kaempferol series: $\mathrm{R}=\mathrm{H}$ Acetylated derivative of the flavonoid: $\mathrm{R}=\mathrm{Ac}$<smiles>O=c1cc(-c2ccc(Oc3cc4c(cc3O)OC(c3ccc(O)cc3)=CC4O)cc2)oc2cc(O)cc(O)c12</smiles>

Hinokiflavone<smiles>CCCCCc1cc(O)cc(O)c1C(=O)Oc1cc(O)c(C(=O)Oc2cc(O)c(C(=O)O)c(CCC)c2)c(CCC)c1</smiles>

Cytonic Acid A<smiles>CCCCCc1cc(OC(=O)c2c(O)cc(OC(=O)c3c(O)cc(O)cc3CCC)cc2CCC)c(O)cc1O</smiles>

Cytonic Acid B<smiles>CC1C=CC(=C2C(=O)NC(CC(N)=O)C2=O)OC1C</smiles>

Z-form

Bripiodionen

Figure 2. Chemical structures of natural products that have shown efficacy in vitro against human cytomegalovirus infection.

viral DNA polymerase site. Studies have shown that mutations in regions II and III are potentially associated with FOS resistance, while deletions or substitutions in region VI lead to multi-drug resistance $(3,20)$.

\section{Natural products}

The emergence of antiviral drug resistance remains an obstacle in the treatment of cytomegalovirus infection with established antiviral drugs. In search of new chemical molecules whose efficacy is not influenced by mutations in the $U L 97$ and $U L 54$ genes, researchers have turned to the field of natural products. Although clinical studies with natural products have yet to be performed, in vitro results indicate that compounds from plants and microorganisms against cytomegalovirus have a high potential. The natural products that have to date been shown to inhibit cytomegalovirus in vitro can be classified into three groups according to their molecular targets (Fig. 2). 
Early viral proteins inhibition. Although the mechanisms of action of flavonoids and biflavonoids remain to be fully understood, it has been suggested that they may affect the entry of HCMV into host cells or the function of early viral proteins $(21,22)$.

Flavonoids are polyphenolic compounds found in fruits and vegetables. In vitro investigations have suggested that they exert not only antiviral, but also anti-microbial and anti-tumor activities $(23,24)$. Interestingly, the acetylated form of flavonoids, belonging to the kaempferol series from the buds of Platanus orientalis, possesses an even higher potency than the non-acetylated molecule (24). The biflavonoids hinokiflavone and volkensiflavone, from Rhus succedanea and Garcinia multiflora, respectively, also exert activity on HCMV (25).

Antiviral polysaccharides. Natural polysaccharides disturb virus-cell interactions and inhibit cytomegalovirus adsorption or penetration into the host cells (8). An example of an antiviral polysaccharide is nostoflan, which is isolated from the terrestrial cyanobacterium Nostoc flagelliform. Cyanobacteria live in extreme conditions and produce polysaccharides in the form of slimes and capsules (26). The chemical components of nostoflan are the sugars glucose, mannose and xylose. The complex chemical structure of this polysaccharide remains to be fully elucidated.

Calcium spirulan (Ca-SP) is a sulfated polysaccharide isolated from the blue-green algae Spirulina platensis, which grows in salty lakes (27). It contains sugars, calcium and sulfate. As with nostoflan, further investigation is needed to clarify its structural formula. However, the antiviral activity of Ca-SP it is known to depend on the presence of sulfated groups, and it has been reported as having higher potency than nostoflan against HCMV infections (26-28).

Rhamnan sulfate is another sulfated polysaccharide isolated from Monostroma latissimum. Unlike the other two polysaccharides, its mechanism of action appears to involve factors besides the inhibition of virus-cell attachment (29).

Protease inhibitors. The third target molecule for natural products represents the serine protease assemblin, a protein which processes the capsid-assembly protein precursor to the mature capsid-assembly protein $(30,31)$. It has been demonstrated that typical mammalian serine protease inhibitors do not inhibit the cytomegalovirus protease, and hence do not possess antiviral activity $(30,31)$. This suggests the need for specific compounds that could efficiently inhibit assemblin. In vitro experiments have suggested that quanolirones I and II, two naphthacenequinones glycosides isolated from Streptomyces strain WC76535, are potential assemblin inhibitors (30). Other members of this class including bripiodionen, extracted from Streptomyces strain WC76599, and the cytonic acids $\mathrm{A}$ and $\mathrm{B}$, isolated from the fungi Cytonaema, also exhibit HCMV protease inhibitory activity $(33,34)$.

\section{Conclusions}

Although the natural products discussed here show considerable inhibition of HCMV infection, none have entered the clinical trial stage, and any conclusions regarding their efficacy in vivo are speculative. Moreover, the literature focusing on the extraction, chemical analysis, and in vitro application of natural products in $\mathrm{HCMV}$-infected cells remains rather limited.

Bearing in mind that natural products are of tremendous value in the treatment of a large number of diseases, it can be speculated that this might also hold true for the treatment of HCMV infections. It is therefore worth expanding the screening of natural products to develop novel treatment options for HCMV. The in vitro data in the literature - though relatively scarce - also indicate that this might be a promising approach.

\section{References}

1. Lin M-F, Wei G-Q, Huang H and Cai Z: Human cytomegalovirus induces alteration in $\beta$-actin mRNA and microfilaments in Human Embryo Fibroblast Cells. J Zhejiang Univ Sci 5: 733-737, 2004.

2. European Bioinformatics Institute, the European Molecular Biology Laboratory: Human herpesvirus causes a range of human disorders including cold sores, roseola, Epstein Barr Virus (EBV) and genital warts. http://www.ebi.ac.uk/2can/genomes/viruses/ Human_herpesvirus.html, January 2008.

3. Gilbert C and Boivin G: Human cytomegalovirus resistance to antiviral drugs. Antimicrob Agents Chemother 49: 873-883, 2005.

4. Landolfo $\mathrm{S}$ and Lembo D: The human cytomegalovirus. Pharmocol Ther 98: 269-297, 2003.

5. Farkas J: Human cytomegalovirus (CMV): immune invasion and vaccine development. http://www.brown.edu/Courses/ Bio_160/Projects1999/ies/hcmv.html, January 2008.

6. Sodeberg-Naucler C, Fish KN and Nelson JA: Reactivation of latent human cytomegalovirus by allogeneic stimulation of blood cells from healthy donors. Cell 91: 119-126, 1997.

7. Sodeberg-Naucler C, Streblow DN, Fish KN, Allan-Yorke J, Smith PP and Nelson JA: Reactivation of latent human cytomegalovirus in CD14+ monocytes is differentiation dependent. J Virol 75: 7543-7554, 2001.

8. Moellering RC and Corey L: Antimicrobial resistance prevention initiative - an update: proceedings of an expert panel on resistance. Am J Med 120: S4-S25, 2007.

9. Littler E, Stuart AD and Chee MS: Human cytomegalovirus UL97 open reading frame encodes a protein that phosphorylates the antiviral nucleoside analogue ganciclovir. Nature 358: 160-162, 1992.

10. Mulamba GB, Hu A, Azad RF, Anderson KP and Coen DM: Human cytomegalovirus mutant with sequence-dependent resistance to the phosphothioate oligonucleotide formivirsen (ISIS 2922). Antimicrob Agents Chemother 42: 971-973, 1998.

11. Baldanti A and Gerna G: Human cytomegalovirus resistance to antiviral drugs: diagnosis, monitoring and clinical impact. J Antimicrob Chemother 52: 324-330, 2003.

12. Chrisp $\mathrm{P}$ and Clissold SP, Foscarnet. A review of its antiviral activity, pharmacokinetic properties and therapeutic use in immunocompromised patients with cytomegalovirus retinitis. Drugs 41: 104-129, 1991.

13. Chulay J, Biron K, Wang L, Underwood M, Chamberlain S, Frick L, Good S, Davis M, Harvey R, Townsend L, Drach J and Koszalka G: Development of novel benzimidazole riboside compounds for treatment of cytomegalovirus disease. Adv Exp Med Biol 458: 129-134, 1999.

14. Evers DL, Komazin G, Ptak RG, et al: Inhibition of human cytomegalovirus replication by benzimidazole nucleosides involves three distinct mechanisms. Antimicrob Agents Chemother 48: 3918-3927, 2004.

15. Krosky PM, Baek MC and Coen DM: The human cytomegalovirus UL97 protein kinase, an antiviral drug target, is required at the stage of nuclear egress. J Virol 77: 905-914, 2003.

16. Rubin RH: Preemptive therapy in immunocompromised hosts. N Engl J Med 324: 1057-1059, 1991.

17. McGavin JK and Goa KL: Ganciclovir - an update of its use in the prevention of cytomegalovirus infection and disease in transplant recipients. Drugs 61: 1153-1183, 2001.

18. Chee MS, Lawrence GL and Barrell BG: Alpha-, beta- and gammaherpesviruses encode a putative phosphotransferase. J Gen Virol 70: 1151-1160, 1989.

19. Smith I, Cherringtin JM, Jiles RE, et al: High level resistance of cytomegalovirus to ganciclovir is associated with alterations in both the UL97 and DNA polymerase genes. J Infect Dis 176: 69-77, 1997. 
20. Cihlar T, Fuller M and Cherrington J: Characterization of drug resistance-associated mutations in the human cytomegalovirus DNA polymerase gene by recombinant mutant viruses generated from overlapping DNA fragments. J Virol 72: 5927-5936, 1998.

21. Aligiannis N, Mitaku S, Mitrocotsa D and Leclerc S: Flavonoids as cycline-dependent kinase inhibitors: inhibition of cdc 25 phosphatase activity by flavonoids belonging to the quercetin and kaempferol Series. Planta Med 67: 468-470, 2001.

22. Evers DL, Chao CF, Wang X, Zhang Z, Huong SM and Huang ES: Human cytomegalovirus-inhibitory flavonoids: studies on antiviral activity and mechanism of action. Antiviral Res 68: 124-134, 2005.

23. Akiyama T, Ishida J, Nakagama $\mathrm{S}$, et al: Genistein, a specific inhibitor of tyrosine-specific protein kinases. J Biol Chem 262: 5592-5595, 1987.

24. Mitaku S: Evaluation of the antiviral activity of kaempferol and its glycosides against human cytomegalovirus. Planta Med 66: 377-379, 2000.

25. Lin Y: Antiviral activities of biflavonoids. Planta Med 65: 120-125, 1999.

26. Hayashi T: Isolation of an antiviral polysaccharide, nostoflan, from a terrestrial cyanobacterium, Nostoc flagelliform. J Nat Prod 68: 1037-1041, 2005.

27. Hayashi T: Calcium spirulan, an inhibitor of enveloped virus replication, from a blue-green alga Spirulina platensi. J Nat Prod 59: 83-87, 1998.
28. Baba M, Pauwels R, Balzarini J, Arnout J, Desmyter J and De Clerq E: Mechanism of inhibitory effect of dextran sulfate and heparin on replication of human immunodeficiency virus in vitro. Proc Natl Acad Sci 85: 6132-6136, 1988.

29. Hayashi T: Antiviral activities against HSV-1, HSV-2, and HIV-1 of rhamnan sulfate from Monostroma latissimu. Planta Med 65 439-441, 1999.

30. Cutrone J: Quanolirones I and II. Two new human cytomegalovirus protease inhibitors produced by Streptomyces sp. WC 76535. J Nat Prod 61: 1379-1382, 1998.

31. Irmiere A and Gibson W: Isolation of human cytomegalovirus intranuclear capsids, characterization of their protein constituents, and demonstration that the B-capsid assembly protein is also abundant in noninfectious enveloped particles. J Virol. 56 277-283, 1985

32. Welch AR, McNally LM, Hall MRT and Gibson W: Herpes-virus proteinase: site-directed mutagenesis used to study maturational, release, and inactivation cleavage sites of precursor and to identify a possible catalytic site serine and histidine. J Virol 67: 7360-7372, 1993.

33. Guo B: Cytonic acids A and B: novel tridepside inhibitors of hCMV protease from the endophytic fungus Cytonaema species. J Nat Prod 63: 602-604, 2000.

34. Shu Y: Bripiodionen, a new inhibitor of the human cytomegalovirus protease from Streptomyces sp. WC 76599. J Nat Prod 60: 529-532, 1997. 